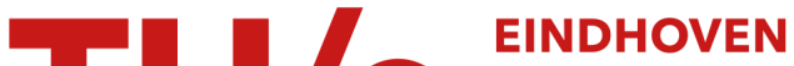 UNIVERSITY OF TECHNOLOGY
}

\section{Photodynamic control of the chain length in supramolecular polymers}

Citation for published version (APA):

Weyandt, E., ter Huurne, G. M., Vantomme, G., Markvoort, A. J., Palmans, A. R. A., \& Meijer, E. W. (2020). Photodynamic control of the chain length in supramolecular polymers: switching an intercalator into a chain capper. Journal of the American Chemical Society, 142(13), 6295-6303. https://doi.org/10.1021/jacs.0c00858

\section{Document license:}

CC BY-NC-ND

DOI:

10.1021/jacs.0c00858

Document status and date:

Published: 01/04/2020

\section{Document Version:}

Publisher's PDF, also known as Version of Record (includes final page, issue and volume numbers)

\section{Please check the document version of this publication:}

- A submitted manuscript is the version of the article upon submission and before peer-review. There can be important differences between the submitted version and the official published version of record. People interested in the research are advised to contact the author for the final version of the publication, or visit the $\mathrm{DOI}$ to the publisher's website.

- The final author version and the galley proof are versions of the publication after peer review.

- The final published version features the final layout of the paper including the volume, issue and page numbers.

Link to publication

\section{General rights}

Copyright and moral rights for the publications made accessible in the public portal are retained by the authors and/or other copyright owners and it is a condition of accessing publications that users recognise and abide by the legal requirements associated with these rights.

- Users may download and print one copy of any publication from the public portal for the purpose of private study or research.

- You may not further distribute the material or use it for any profit-making activity or commercial gain

- You may freely distribute the URL identifying the publication in the public portal.

If the publication is distributed under the terms of Article 25fa of the Dutch Copyright Act, indicated by the "Taverne" license above, please follow below link for the End User Agreement:

www.tue.nl/taverne

Take down policy

If you believe that this document breaches copyright please contact us at:

openaccess@tue.nl

providing details and we will investigate your claim. 


\title{
Photodynamic Control of the Chain Length in Supramolecular Polymers: Switching an Intercalator into a Chain Capper
}

\author{
Elisabeth Weyandt, Gijs M. ter Huurne, Ghislaine Vantomme, Albert J. Markvoort, Anja R. A. Palmans,
} and E. W. Meijer*

Cite This: J. Am. Chem. Soc. 2020, 142, 6295-6303

Read Online

\section{ACCESS | Llll Metrics \& More | 回 Article Recommendations | (s) Supporting Information}

ABSTRACT: Supramolecular systems are intrinsically dynamic and sensitive to changes in molecular structure and external conditions. Because of these unique properties, strategies to control polymer length, composition, comonomer sequence, and morphology have to be developed for sufficient control over supramolecular copolymerizations. We designed photoresponsive, mono acyl hydrazone functionalized benzene-1,3,5-tricarboxamide (m-BTA) monomers that play a dual role in the coassembly with achiral alkyl BTAs (a-BTA). In the E isomer form, the chiral m-BTA monomers intercalate into stacks of a-BTA and

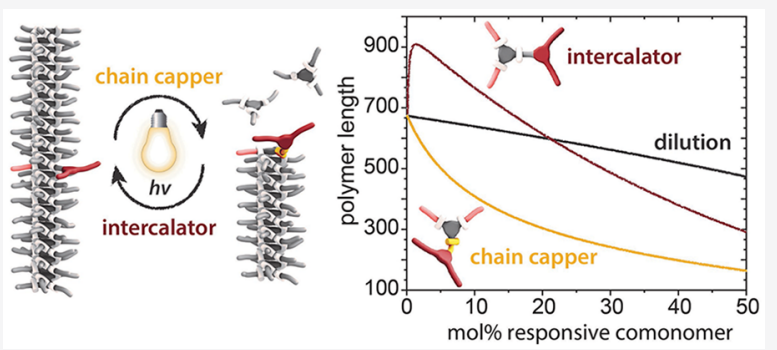
dictate the chirality of the helices. Photoisomerization to the $Z$ isomer transforms the intercalator into a chain capper, allowing dynamic shortening of chain length in the supramolecular aggregates. We combine optical spectroscopy and light-scattering experiments with theoretical modeling to show the reversible decrease in length when switching from the $E$ to $Z$ isomer of $\mathbf{m - B T A}$ in the copolymer with inert a-BTA. With a mass-balance thermodynamic model, we gain additional insights into the composition of copolymers and length distributions of the species over a broad range of concentrations and mixing ratios of a-BTA/m-BTA. Moreover, the model was used to predict the impact of an additive (chain capper and intercalator) on the chain length over a range of concentrations, showing a remarkable amplification of efficiency at high concentrations. By employing a stimuli-responsive comonomer in a mostly inert polymer, we can cooperatively amplify the effect of the switching and obtain photocontrol of polymer length. Moreover, this dynamic decrease in chain length causes a macroscopic gelto-sol phase transformation of the copolymer gel, although $99.4 \%$ of the organogel is inert to the light stimulus.

\section{INTRODUCTION}

Although the field of supramolecular polymers has made exciting progress, many challenges remain in controlling supramolecular copolymerization, morphologies, composition, and aggregate length. ${ }^{1-3}$ When examining copolymerizations of two monomers, the influence of a second component on the length of the structures formed is often not considered. However, these features are of paramount importance for the resulting properties of the system and hence for their use in novel applications. A second component in supramolecular polymerizations can influence the degree of polymerization in many ways by acting as a comonomer, an intercalator, a sequestrator, or a chain capper. Controlling the chain length of isodesmic supramolecular polymers has been achieved by adding monotopic comonomers (chain cappers), which leads to an efficient reduction in chain length. ${ }^{4-8}$ For cooperative supramolecular polymerization, however, the two reactive sites of the faces of the monomers are electronically coupled, leading to either monomeric and small species or long polymer chains coexisting in solution. ${ }^{9}$ In recent years many elegant examples have been reported that achieved kinetic control over aggregate length by using pre-equilibrated seeds, tailored initiators, or metastable monomers. ${ }^{10-14}$ In addition, previous studies have elegantly demonstrated the ability to control the polymerization and depolymerization of supramolecular homopolymers with light or other stimuli through the creation of defects and depolymerizing through the buildup of steric strain. ${ }^{16,17}$

In the field of molecular switches, stimuli-responsive molecules have been excessively studied to translate molecular conformational changes into macroscopic events in supramolecular polymers and liquid crystals (phase transitions or changes in aggregation affinity). ${ }^{18-20}$ Although $\mathrm{pH}^{21}$ temperature, and magnetic as well as electric fields ${ }^{22}$ are often exploited, light is by far the most popular stimulus as it offers excellent spatiotemporal resolution, it is green, and it can easily be dosed and controlled. ${ }^{23-28}$ The types of systems that exhibit photoresponsive behavior can be broadly separated into three categories: (1) switching of single molecules in solution, (2)

Received: January 22, 2020

Published: March 13, 2020 
Scheme 1. Molecular Structure of (a) Mono Acyl Hydrazone Functionalized BTA (m-BTA), (b) Achiral Octyl BTA (a-BTA) Monomers, and (c) Copolymer Formed by Intercalation of Chiral m-BTA into Helical Stacks of a-BTA
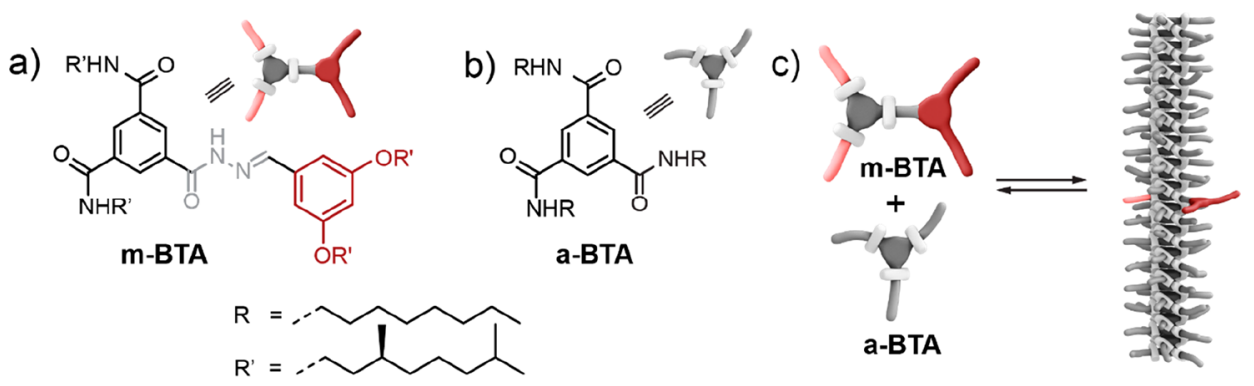

switching in supramolecular systems (e.g., fibers, tubes, gels, and micelles), and (3) switching in mobile bulk phases such as liquid crystals. For the switching in liquid crystal systems many examples have been reported where only dopant quantities (typically $<5 \%$ ) in an inert matrix are sufficient to induce responsive behavior of the overall materials. ${ }^{29-33}$ For the switching in solution and in supramolecular system, however, usually all of the molecules composing the system contain the responsive unit undergoing photoisomerization. ${ }^{16,34}$ To our knowledge, only few studies reported macroscopic effects from the isomerization of low molar quantities (5-10 mol \%) of responsive monomers in a supramolecular coassembly. ${ }^{35-40}$

Benzene-1,3,5-tricarboxamide (BTA)-based supramolecular polymers are a unique class of monomers as they readily assemble and reach the thermodynamic equilibrium within a few seconds. Because of the simplicity of design and fast equilibration of the BTAs, they are an ideal system to study and understand the interactions with more complex molecules. Many groups are using this basic structure to unravel novel concepts in dynamic systems, while our group recently reported on the interaction of BTA monomers with supramolecular competitors as an alternative approach to regulate the length of supramolecular polymers. ${ }^{15}$

Here, we report on a supramolecular system sensitive to light although only minor quantities of its constituents are photoactive. The system is based on a two-component polymerization of chiral, mono acyl hydrazone functionalized BTAs (m-BTA) with achiral alkyl BTAs (a-BTA, Scheme 1). Acyl hydrazones are well-known for their use as conformational switches by metal coordination ${ }^{41,42}$ and in dynamic combinatorial chemistry, ${ }^{43-45}$ and they have also gained attention and popularity as a new class of modular and potent photoswitches. $^{30,46-50}$ They feature a complementary hydrogen bond donor/acceptor $\mathrm{C}(=\mathrm{O})-\mathrm{NH}$ unit and a photoisomerizable $\mathrm{C}=\mathrm{N}$ double bond. ${ }^{51,52}$ Compared to other photochromic groups, they offer excellent stabilities as well as good efficiency and band separation and are readily accessible from commercially available starting materials. ${ }^{47,53,54}$ We show how the acyl hydrazone monomers, although not able to form homopolymers, copolymerize with a-BTA into light-responsive copolymers. Photoisomerization of the m-BTA monomer from the $E$ to the $Z$ isomer transforms m-BTA from an intercalating comonomer to a supramolecular chain capper, effectively decreasing the degree of polymerization of the copolymers after light irradiation. The cooperativity of the aBTA/m-BTA copolymers allows the local changes in the chromophore structure to be amplified, thereby reversibly decreasing the degree of polymerization upon light irradiation.

\section{RESULTS}

Molecular Design, Synthesis, and Solid State Aggregation of BTA Monomers. We synthesized and characterized an acyl hydrazone BTA derivative (m-BTA) comprising one amide fused with an acyl hydrazone motif and studied its properties as a photoresponsive, supramolecular monomer (Scheme 1a). The two central core amides of $\mathbf{m}$ BTA and the 3,5-position on the phenyl ring of the acyl hydrazone were functionalized with chiral $(S)$-3,7-dimethyloctyl alkyl chains to enhance solubility and introduce helical bias in the supramolecular polymer. The molecular structure of $\mathbf{m}$ BTA features a similar self-complementary amide array as the achiral alkyl BTA (a-BTA, Scheme 1b), ${ }^{55}$ therefore allowing us to study the homo- and copolymerization of both monomers. We hypothesize that the chiral m-BTA monomers will act as supramolecular sergeants, ${ }^{56,57}$ dictating the helicity of the aBTA soldier stacks, even at low molar percentages of additive (Scheme 1c).

The synthesis of m-BTA is described in the Supporting Information (Figures S1 and S2) and was conducted in good overall yield (71\%). Commercially available 3,5-dihydroxybenzaldehyde was functionalized with (S)-3,7-dimethyloctyl side chains in a Williamson ether coupling. To get the final compounds, the mono methylbenzene carboxylate derivative was transformed into a hydrazide and reacted with the substituted aldehyde in an acid-catalyzed condensation reaction. ${ }^{46,58}$ The synthesis of a-BTA has been reported previously. ${ }^{55}$ The compounds were characterized by ${ }^{1} \mathrm{H}$ and ${ }^{13} \mathrm{C}$ NMR, MALDI-TOF, and FT-IR.

Infrared spectroscopy allows for the comparison of the donor/acceptor properties of the amide groups fused to the acyl hydrazone versus the regular BTA amide groups. For aBTA the NH I stretch is typically found at $3307 \mathrm{~cm}^{-1}$, the $\mathrm{C}=$ $\mathrm{O}$ stretch at $1644 \mathrm{~cm}^{-1}$, and amide II at $1532 \mathrm{~cm}^{-1}$, indicative of lateral intermolecular hydrogen bonding in the bulk (Figure S3). ${ }^{55}$ The mono acyl hydrazone derivative m-BTA bears two different types of amides, and also two corresponding $\mathrm{NH} \mathrm{I}$ bands were observed at 3291 and $3187 \mathrm{~cm}^{-1}$. The $\mathrm{C}=\mathrm{O}$ band was found at $1649 \mathrm{~cm}^{-1}$ and amide II at $1545 \mathrm{~cm}^{-1}$, slightly shifted compared to a-BTA. These results imply that the two types of amide groups possess different donor/acceptor properties, which will most likely also affect their ability and mechanism of polymerization into supramolecular aggregates.

Homoaggregation and Photoisomerization of $\mathrm{m}-\mathrm{BTA}$ in Apolar Solvents. While a-BTA readily forms supramolecular polymers through 3-fold hydrogen bonding in apolar solvents such as methylcyclohexane $(\mathrm{MCH})$, m-BTA monomers are molecularly dissolved at the same conditions. Even at concentrations higher than $c=1 \mathrm{mM}$ in $\mathrm{MCH}$ no temperature- 
a)

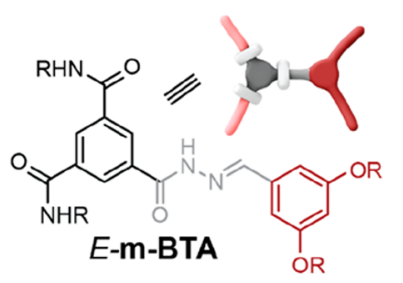

b)

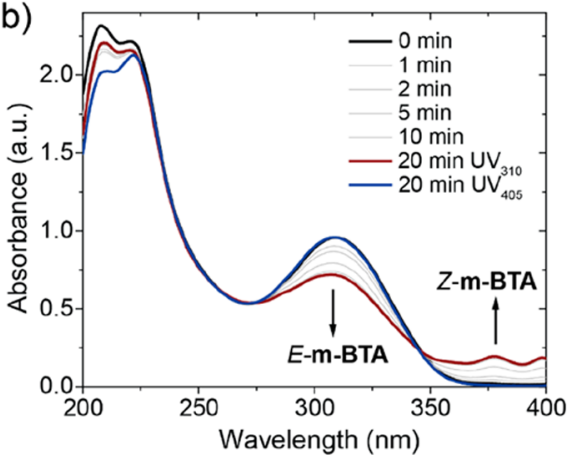

$\underset{h v^{\prime} \text { or d } T}{\stackrel{h v}{\rightleftarrows}}$

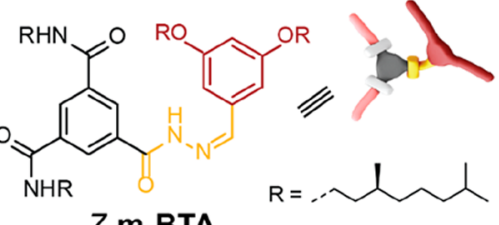

Z-m-BTA

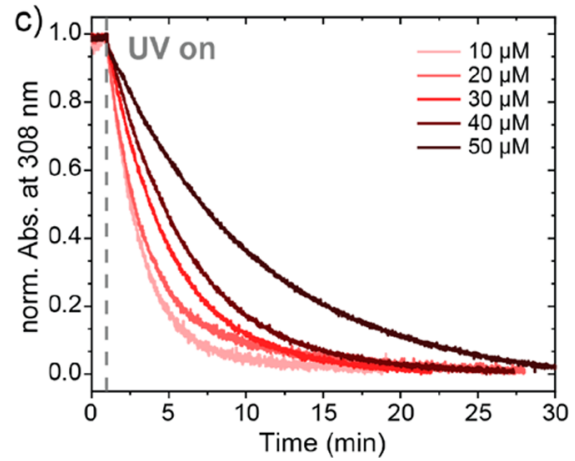

Figure 1. (a) Light-induced isomerization from the planar $E$ isomer to the $Z$ isomer of m-BTA. (b) Spectral changes with prolonged times of irradiation with UV light of $\lambda=310$ or $405 \mathrm{~nm}$. The band corresponding to the $E$ isomer at $\lambda=308 \mathrm{~nm}$ decreases, and a new band from the $Z$ isomer arises around $\lambda=375-405 \mathrm{~nm}$ when irradiated with $\mathrm{UV}_{310}(c=50 \mu \mathrm{M}$ in $\mathrm{MCH})$. (c) Decrease of the $E$ isomer band upon irradiation for solutions of $c=10-50 \mu \mathrm{M}$ in $\mathrm{MCH}$.
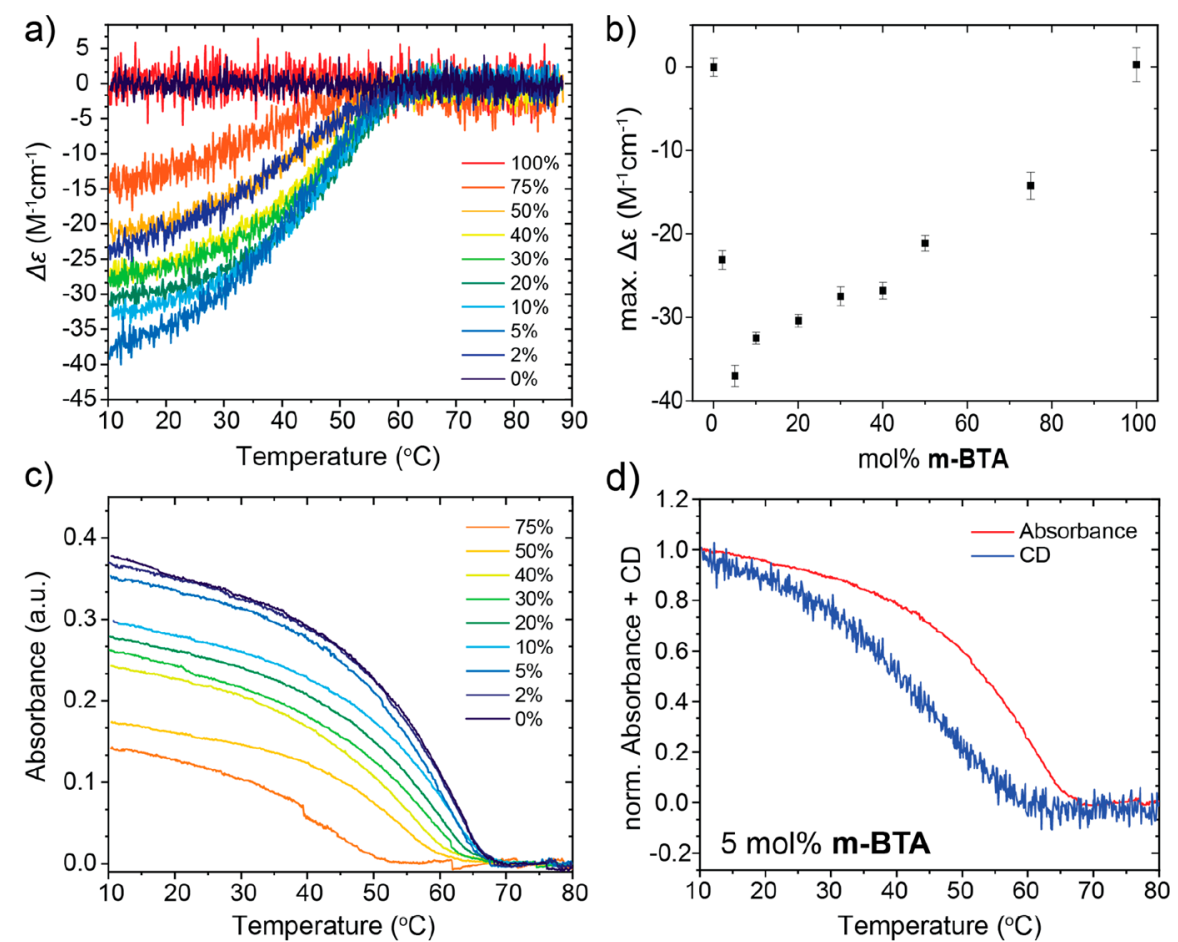

Figure 2. Copolymerization of chiral acyl hydrazone functionalized E-m-BTA with a-BTA. (a) CD melting curves of copolymer mixtures (cooling rate $=1 \mathrm{~K} \mathrm{~min}^{-1}$ ). (b) $\mathrm{CD}$ maximum determined by averaging the $\Delta \varepsilon$ value at $223 \mathrm{~nm}$ in (a) between 10 and $15^{\circ} \mathrm{C}$ for the different ratios of $E$-mBTA/a-BTA (error bars indicate standard deviation). (c) UV melting curves showing decrease in $T_{\mathrm{e}}$ with increasing mol \% E-m-BTA of the copolymer mixtures. (d) Normalized CD and absorbance melting curves $\left(c_{\text {tot }}=25 \mu \mathrm{M}\right.$ in $\mathrm{MCH}$, signal probed at $\left.\lambda=223 \mathrm{~nm}\right)$.

dependent changes in the absorbance or circular dichroism (CD) signal were observed that would indicate aggregation. FT-IR experiments of $\mathbf{m}$-BTA and a-BTA at $2.0 \mathrm{mM}$ in $\mathrm{MCH}$ also found significantly different hydrogen-bonding patterns (Figure S4). While a-BTA exhibited a band at around 3250 and $1650 \mathrm{~cm}^{-1}$ typical for triple hydrogen bonded, helical arrangement in solution, for m-BTA those bands were not present or shifted, indicating that they are not assembled as a-
BTA. To investigate the $E$ to $Z$ isomerization of the acyl hydrazone monomer (Figure 1a), solutions of m-BTA in $\mathrm{MCH}$ were irradiated with UV light $(\lambda=310 \mathrm{~nm})$ for $1 \mathrm{~min}$ periods during the first $5 \mathrm{~min}$ and then for longer periods until $20 \mathrm{~min}$ of total irradiation time. Absorbance spectra were recorded after each irradiation step. In the absorbance spectra, the band of E-m-BTA at $\lambda=308 \mathrm{~nm}$ decreased, and a new 

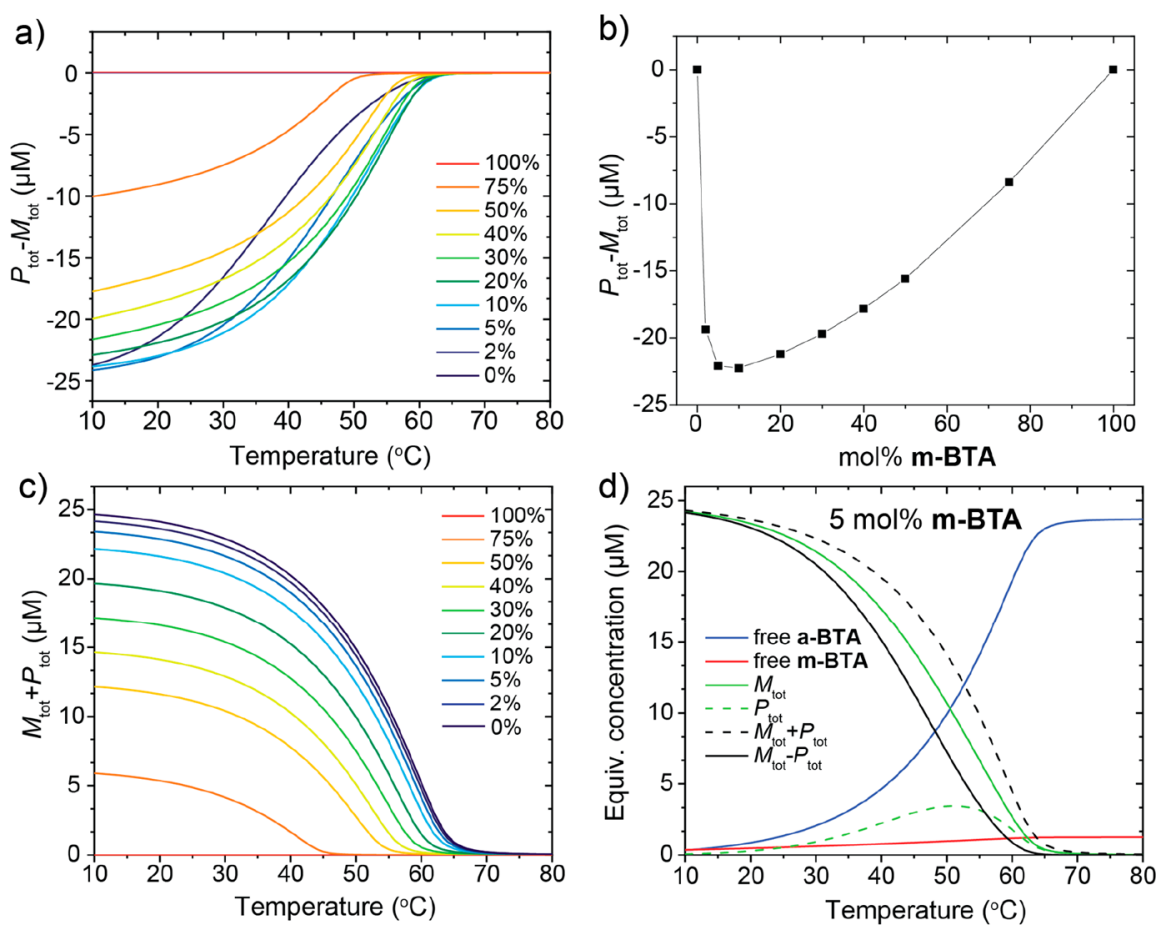

Figure 3. Theoretical modeling of the copolymerization of E-m-BTA/a-BTA. (a) Calculated $P_{\text {tot }}-M_{\text {tot }}$ over a range of temperatures (curves of 0 and $100 \mathrm{~mol} \% \mathbf{m}$-BTA overlap at zero) and (b) with increasing mol \% m-BTA at $25{ }^{\circ} \mathrm{C}$. (c) $M_{\text {tot }}+P_{\text {tot }}$ curves for the copolymer mixtures with increasing mol \% of E-m-BTA. (d) Specimen plot of a $5 \mathrm{~mol} \%$ mixture of $E$-m-BTA in a-BTA (calculations based on $c_{\text {tot }}=25 \mu \mathrm{M}$ in MCH, $\Delta H_{M A B}=-46.5 \mathrm{~kJ} \mathrm{~mol}^{-1}, \Delta S_{A B}=-54.2 \mathrm{~J} \mathrm{~mol}^{-1} \mathrm{~K}^{-1}$, and $\left.\Delta H_{P}^{\text {pen }}=2 \mathrm{~kJ} \mathrm{~mol}^{-1}\right)$.

broad band at $\lambda=375-405 \mathrm{~nm}$ corresponding to the $Z$-mBTA appeared (Figure 1b).

To investigate the kinetics of the isomerization, the wavelength of maximum absorption of E-m-BTA at $\lambda=308$ $\mathrm{nm}$ was monitored over time while irradiating with UV light in situ (Figure 1c). Initially, the band decreases rapidly until a plateau is reached at around half an hour at a concentration of $c=50 \mu \mathrm{M}$ m-BTA. Irradiation with UV light of $\lambda=405 \mathrm{~nm}$ reverses the process, and the original absorbance spectrum is recovered. ${ }^{46}$ To prepare an effective, photoresponsive material, the reversibility of the photoswitch is crucial. Therefore, the switching cycle was repeated up to six times without visible fatigue of the acyl hydrazone monomers (Figure S5). The thermal half-time of the photoswitch was determined to be $t_{1 / 2}$ $=2.3 \mathrm{~h}$ by monitoring the recovery of the $E$-m-BTA band over time at $25{ }^{\circ} \mathrm{C}$ (Figure S6). The switching of $\mathbf{m}$-BTA can thus be reversed by light or by thermal equilibration.

Spectroscopic Investigation of the Copolymerization of $\mathbf{m}-\mathrm{BTA}$ and a-BTA. The molecular structure of $\mathbf{m}$-BTA is similar to alkyl BTAs such as a-BTA, with two aliphatic side chains connected on the amide groups of the central core. Upon mixing $5 \mathrm{~mol} \%$ of E-m-BTA with a-BTA, we discovered that a copolymer was formed through cooperative supramolecular copolymerization with a strong $\mathrm{CD}$ signal at $\lambda_{\max }=$ $223 \mathrm{~nm}$ (Figure S9 and Figure 2a). The E-m-BTA monomers serve as chiral sergeants and dictate the formation of helical aggregates with a helical bias in the coassembly with a-BTAs. To understand the mixing of the two components, we prepared a number of copolymer solutions with increasing mol \% E-mBTA, keeping the total monomer concentration constant at $c_{\text {tot }}$ $=25 \mu \mathrm{M}$. The amplification of chirality in these Sergeants-andSoldiers experiments reaches its maximum $\mathrm{CD}$ effect of $\Delta \varepsilon=$ $-38 \mathrm{M}^{-1} \mathrm{~cm}^{-1}$ at around $5 \mathrm{~mol} \%$ E-m-BTA in the assembly, which is comparable to the amplification of chirality with chiral alkyl BTAs or related BTA based monomers previously reported by our group. ${ }^{56,59}$ Interestingly, the maximum CD value measured for the copolymer mixtures $\left(c_{\text {tot }}=25 \mu \mathrm{M}\right.$ in $\mathrm{MCH})$ initially increases with increasing percentages of chiral comonomer (2-5 mol \% m-BTA) but decreases with higher percentages of comonomer (10-100 mol \%, Figure $2 \mathrm{~b})$. As the m-BTA monomers do not homopolymerize but form copolymers, we concluded that they act as an intercalator in the a-BTA stacks. An intercalator, unlike a comonomer, can insert between monomers of a different type but has no affinity to form homoaggregates. At high mol \% of E-m-BTA, the CD signal therefore decreases as there is less a-BTA monomer available for aggregate formation. The shape of the CD spectra observed for the copolymer mixtures resembles the shape obtained with low quantities of chiral alkyl BTAs with no additional Cotton effect at the $\pi-\pi^{*}$ transition absorbance band at $\lambda=308 \mathrm{~nm}$ of the hydrazone chromophore (Figure S9) ${ }^{52}$ Remarkably, the chiral side chains of $\mathbf{m}$-BTA dictate the helicity of the copolymer stacks, while the $\pi-\pi^{*}$ transition of the acyl hydrazone is optically inactive.

The temperature of elongation $\left(T_{\mathrm{e}}\right)$ at which the elongation of supramolecular polymers becomes favorable can be determined from variable-temperature UV experiments. For copolymer mixtures the experimentally found $T_{\mathrm{e}}$ decreases with addition of the intercalator E-m-BTA (Figure $2 c$ and Figure S8) but less than with pure dilution of a-BTA (Figures S7 and S8). This result indicates that the two monomers copolymerize. When comparing the $T_{\mathrm{e}}$ obtained from variabletemperature $\mathrm{CD}$ and UV experiments, for $5 \mathrm{~mol} \%$ E-m-BTA mixed with a-BTA a difference of around $8{ }^{\circ} \mathrm{C}$ can be observed, suggesting that at $65{ }^{\circ} \mathrm{C}$ both $P$ - and $M$-helices are formed, and only at lower temperature the helicity is fully 
biased by the sergeants (Figure $2 \mathrm{~d}$ ). This difference in $T_{\mathrm{e}}$ becomes less pronounced with increasing ratio of E-m-BTA (Figure S10).

Theoretical Modeling of Copolymerization. To understand the underlying mechanism and effects of the comonomer on the chain length, we employed the copolymerization massbalance model previously published. ${ }^{61,62}$ With this general model, we describe the two-component assembly of m-BTA and a-BTA. As a first step, a dilution series of the homopolymerization of a-BTA (monomer $A$ in the model) is investigated, assuming that the monomers assemble in equal number of $M$ - and $P$-aggregates. From the experimental melting curves of a-BTA, the thermodynamic parameters obtained for enthalpy $\left(\Delta H_{A A}\right)$, entropy $\left(\Delta S_{A A}\right)$, and nucleation penalty $\left(\Delta H_{\text {nuc }}^{\text {pen }}\right)$ were identical to the values previously reported by Das et al. ${ }^{60}$ Using those values, the model predicts the degree of polymerization $(\Phi)$ of the homopolymers of pure soldier a-BTA and the polymer length at different concentrations and temperatures (Figures S11 and S12).

Next, the case of a two-component assembly with E-m-BTA (monomer $B$ in the model) intercalating into the stacks of aBTA was considered. The E-m-BTA monomers are chiral, so preferential mixing into $M$-type aggregates is assumed by setting a penalty for mixing into $P$-helices. As m-BTA does not homopolymerize, only $A-B$ or $B-A$ bonds can be formed, but no $B-B$ bonds, i.e., the property of an intercalator. We express the Gibbs free energy changes of these hetero bond formations in an enthalpy $\left(\Delta H_{M A B}\right)$ and an entropy $\left(\Delta S_{M A B}\right)$ parameter as well as an additional mismatch penalty $\left(\Delta H_{P}^{\text {pen }}\right)$ for mixing into the nonpreferred helical aggregate type for the copolymer system (see the Supporting Information for details). Consecutively, the temperature-dependent melting curves and distributions of species for the different copolymer mixtures can be calculated (Figure $3 \mathrm{a}-\mathrm{d}$ and Figures S14S16). The calculated curves are in good agreement with the experimental curves. Similar to the experimentally observed difference in $T_{\mathrm{e}}$ from UV or CD curves, the model also shows the difference in helical bias when comparing the total number of monomers in aggregates $\left(M_{\text {tot }}+P_{\text {tot }}\right)$ with the difference in the number of monomers in aggregates of unpreferred and preferred helicity $\left(M_{\text {tot }}-P_{\text {tot }}\right.$, Figure $3 \mathrm{~d}$ and Figure S16). The model also predicts an initial increase in polymer length at low sergeant concentrations $(2-10 \mathrm{~mol} \%$ E-m-BTA) due to the preferred formation of $M$-aggregates followed by a decrease in length from higher sergeant concentrations (20-75 mol \%) when more intercalator than monomer is present (Figure S15).

Light-Induced Chain Length Modulation of a-BTA Polymers with m-BTA. After establishing the intercalation of E-m-BTA into a-BTA stacks, we studied the consequences of the photoisomerization of E-m-BTA into Z-m-BTA in the coassembly with a-BTA (inert comonomer) on the length and structure of the copolymers. Because of the sensitivity of the supramolecular systems to external triggers, it is hypothesized that the isomerization of small amounts of photoresponsive monomers in the copolymer should be sufficient to affect the overall assembly, through amplification of the stimulus in the cooperative a-BTA system.

Upon irradiation of a copolymer gel $\left(6 \mathrm{wt} \%\right.$ in $\mathrm{MCH}, c_{\mathrm{tot}}=$ $66 \mathrm{mM}$ ) of a-BTA doped with $10 \mathrm{~mol} \%$ m-BTA, a macroscopic phase transformation from the gel to a liquid was induced, although $99.4 \%$ of the organogel is inert to light (Figure 4). The process is fully reversible by heating to $90{ }^{\circ} \mathrm{C}$ or irradiation with $\mathrm{UV}_{405}$ light and allowing for re-equilibration

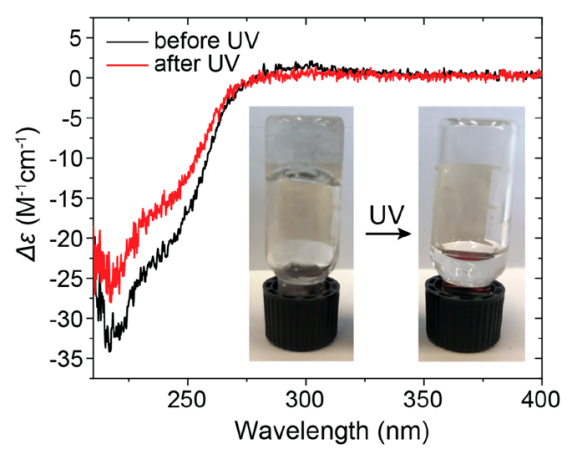

Figure 4. Effect of light irradiation on m-BTA/a-BTA copolymers. (a) Decrease in CD intensity of $10 \mathrm{~mol} \% \mathrm{~m}$-BTA in a-BTA after 15 min of $\mathrm{UV}_{310}$ irradiation $\left(c_{\text {tot }}=25 \mu \mathrm{M}\right.$ in $\left.\mathrm{MCH}\right)$. Inset: gel-to-sol transformation of a copolymer gel of $10 \mathrm{~mol} \%$ m-BTA in a-BTA $(6$ wt \% in $\mathrm{MCH}$ ) upon irradiation.

at room temperature for $2 \mathrm{~h}$. After the isomerization cycle a stable gel was recovered, which could withstand the tube inversion test. In a control experiment with a homopolymer gel of the same effective a-BTA concentration (5.4 wt \% in $\mathrm{MCH}$ ), no changes were observed before and after irradiation. The photoisomerization of a small amount (0.6 wt \%) of photoresponsive monomers of the coassembly appears to be enough to locally break the network of fibers and reach the threshold of the sol-gel transition, expressed visibly on the macroscopic scale by the destruction of the gel. ${ }^{27}$ Similar experiments performed at $c_{\text {tot }}=25 \mu \mathrm{M}$ showed minor changes in the $\mathrm{CD}$ spectrum before and after irradiation (Figure 4). The equilibration and chiral amplification when adding either $E$ - or Z-m-BTA to a solution of a-BTA occurred within seconds, suggesting a highly dynamic exchange and interactions of both isomers with the a-BTA stacks. This result together with the gel-to-sol transition suggests that the Z-mBTA isomers still coassemble with a-BTA but decrease the fiber length. We hypothesize that m-BTA transforms from an intercalator to a chain capper of the a-BTA stacks upon isomerization from E-m-BTA into the Z-m-BTA isomer, where the nonplanar $Z$-m-BTA monomer blocks the chain ends to further addition of a monomer through steric hindrance. As a result, the average degree of polymerization ( $\Phi$, average amount of monomers per polymer) will decrease as evidenced by the sol-gel transformation. The average degree of aggregation ( $\alpha$, fraction of monomers in an aggregate), however, should be less affected, as most monomers are still in an aggregate, though shorter in length.

Static Light Scattering Reveals Changes in Chain Length. To probe the effects of irradiation on the average degree of polymerization and to confirm the role of $Z$-m-BTA as a chain capper, we conducted a series of static light scattering (SLS) experiments. To determine the length of the copolymers, scattering curves of m-BTA/aBTA copolymers $\left(2-50 \mathrm{~mol} \% \mathrm{~m}\right.$-BTA, $c_{\text {tot }}=2.0 \mathrm{mM}$ in $\left.\mathrm{MCH}\right)$ were measured (Figure 5a). The experimental curves were fitted with a cylindrical model to obtain the length of the aggregates. ${ }^{63}$ Scattering profiles were recorded before, after $U_{310}(E$ to $Z$ isomerization) and after $U_{405}$ irradiation ( $Z$ to $E$ backisomerization) for all copolymer ratios (Figure S22) to show the difference in length for the intercalator and chain capper cases. Additionally, we measured the Rayleigh ratio $\left(R_{\theta}\right)$ at a fixed angle to monitor the progress of photoisomerization in real time (Figure 5b, Figures S20 and S21). For $10 \mathrm{~mol} \%$ of 

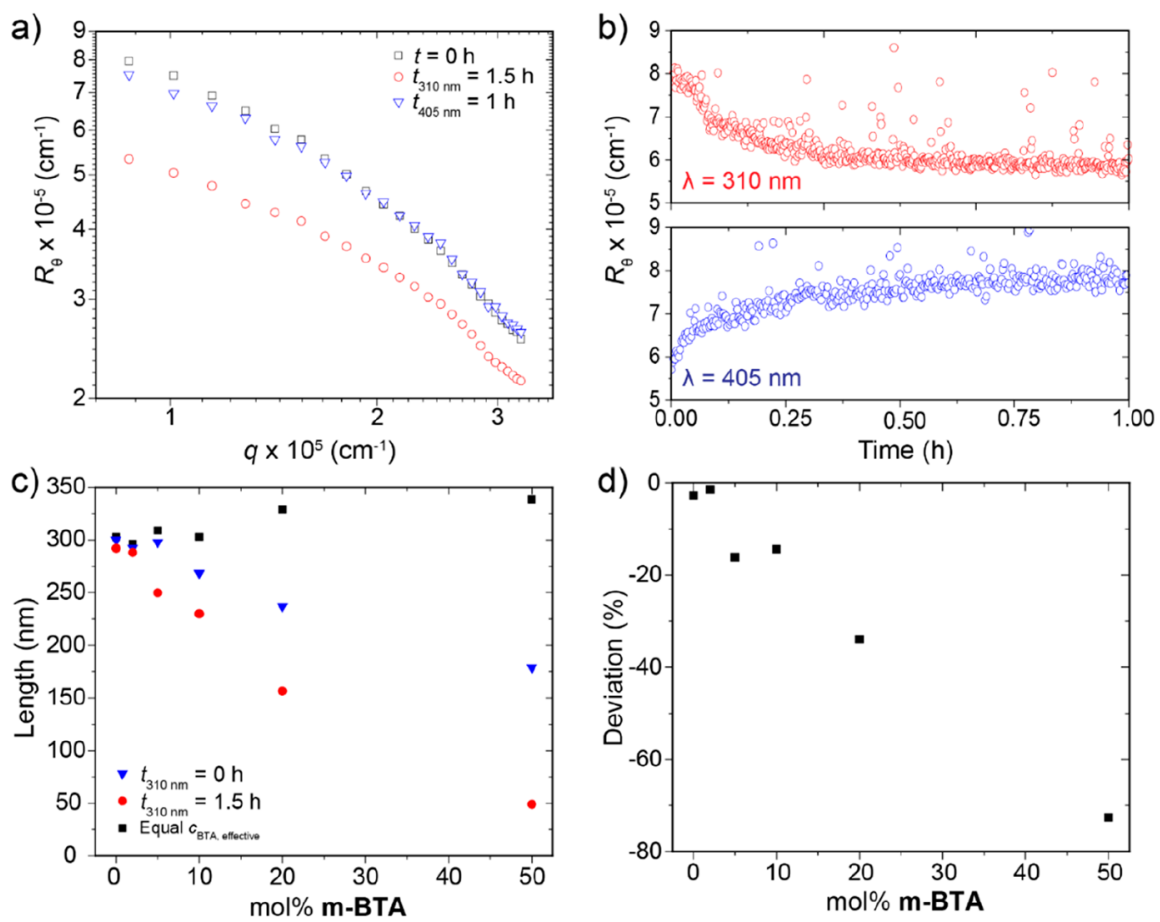

Figure 5. Decrease in copolymer length determined by SLS when switching m-BTA from an intercalating comonomer (E-m-BTA) to a chain capper (Z-m-BTA) with light. (a) Scattering profiles of $10 \mathrm{~mol} \% \mathbf{m}$-BTA in a-BTA before, after $\mathrm{UV}_{310}$, and after $\mathrm{UV}_{405}$ irradiation. (b) Decrease in $R_{\theta}$ for $5 \mathrm{~mol} \% \mathrm{~m}$-BTA in a-BTA at an angle of $30^{\circ}$ followed during $E$ to $Z$ isomerization and $Z$ to $E$ back-isomerization. (c) Effect of light stimulus on the chain length of the copolymers of $\mathbf{m}$-BTA/a-BTA over a range of copolymer compositions. (d) Deviation of chain length in a-BTA/m-BTA stacks before and after irradiation with increasing mol \% m-BTA. Total concentration was $c=2.0 \mathrm{mM}$ in $\mathrm{MCH}$ in all cases.

m-BTA in a-BTA, the weight-average length decreases from approximately 269 to $230 \mathrm{~nm}$ by $\mathrm{UV}_{310}$ irradiation. When isomerizing back from $Z$ to $E$ isomers with $\mathrm{UV}_{405}$ irradiation, $R_{\theta}$ increases until the scattering profile overlaps with the nonirradiated sample (Figure $5 \mathrm{a}, \mathrm{c}$ ), which suggests that the length and morphology of the aggregates is the same as for the nonirradiated samples and that the process is reversible.

To quantify the changes in chain length upon mixing and photoisomerization, the copolymer mixtures were compared to pure diluted a-BTA samples of the same effective concentration $\left(c_{\text {eff }}\right)$, not containing the photoresponsive m-BTA comonomer. The polymer length for the samples of same $c_{\text {eff }}$ remains constant, only a slight increase is observed as we measure slightly above the critical entanglement concentration of the fibers to keep a good signal-to-noise ratio (Figure 5c, black squares). ${ }^{63}$ In accordance with the predictions from the theoretical model, we observe that copolymers of E-m-BTA/aBTA show a decrease in length above $10 \mathrm{~mol} \%$ of E-m-BTA intercalating to the stacks (Figure $5 c$, blue triangles) due to the decrease of a-BTA concentration and the destabilization of the a-BTA/m-BTA stacks.

When irradiating the solutions, a decrease in length is observed for all m-BTA/a-BTA mixtures (Figure 5c, red dots). The decrease in length becomes more pronounced with increasing mol \% of m-BTA. The plot of the percentage of deviation in chain lengths before and after irradiation clearly shows the large changes in polymer length, which we attribute to the transformation of m-BTA comonomers from intercalators to chain cappers (Figure 5d).

These observations were rationalized by using the thermodynamic model. To describe the two-component system after photoisomerization, the model was extended for Z-m-BTA acting as a chain capper by prohibiting the formation of $B-A$ bonds as additional assumption. Aggregates with $B$ monomers at the chain end thus cannot grow further. For this chain-capping case, the model predicts a decrease in mean aggregate length with increasing mol \% of chain capper, which is even stronger than the experimentally observed effect (Figure S18). The model used for understanding the coassembly of E-m-BTA in the a-BTA stacks assumes that the system is always at thermodynamic equilibrium and that $100 \%$ of E-m-BTA converts to Z-m-BTA. Because of the thermal reisomerization of the chain capper Z-m-BTA over time, this assumption does not hold, which makes an exact prediction of the degree of polymerization difficult.

\section{DISCUSSION}

With the insights obtained from the spectroscopy and SLS data combined with the theoretical model, we can control the influence of the second component m-BTA on the chain length of the supramolecular copolymer with E-m-BTA acting as an intercalator and Z-m-BTA as a chain capper. Moreover, it is demonstrated that polymer length is highly dependent on the concentration regime and that the composition of the system changes with concentration. The polymer chain length was calculated with the model over a range of concentrations from $25 \mu \mathrm{M}$ to $40 \mathrm{mM}$ with increasing $\mathrm{mol} \%$ of additive $\mathbf{m}$ BTA (Figure S18). The predicted length was then normalized to the value for the polymer length at $0 \mathrm{~mol} \% \mathbf{m}$-BTA for all concentrations to visualize the relative changes over the concentrations (Figure 6). For the simplest case of dilution of pure a-BTA, the length decreases and scales with the square root of the concentration. Therefore, the decrease in normalized length is identical for the five concentrations plotted in Figure 6 (black lines) although the non-normalized lengths differ (Figure S18). When E-m-BTA acts as an 


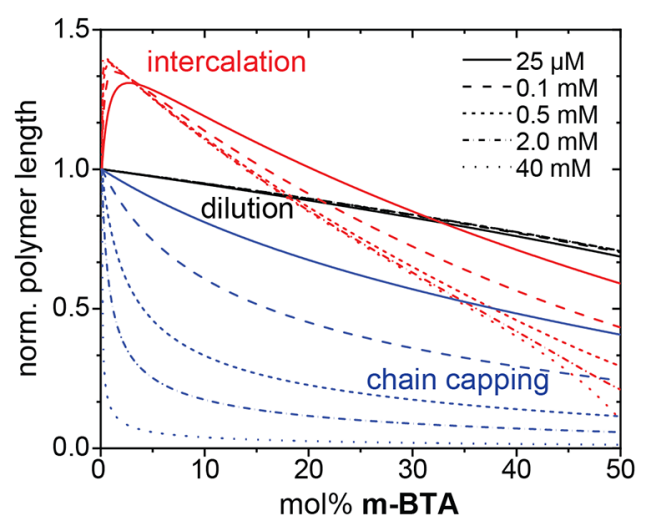

Figure 6. Influence of concentration on decrease of chain length for dilution of a-BTA (black lines), for m-BTA as an intercalator (red lines), and as a chain capper (blue lines). The effects of the additive on the chain length predicted by the thermodynamic model are small at lower concentrations but become much more pronounced at higher concentration.

intercalator (red lines), the chain length varies in two regimes. At first, the chain length increases when predominantly $M$-type helices are formed at the expense of $P$-type helices by intercalation of the chiral comonomer. From roughly $20 \mathrm{~mol} \%$ of E-m-BTA intercalator, the copolymers are shorter than the pure a-BTA aggregates of the dilution series at the same effective concentration because of the decrease of a-BTA concentration and the destabilization of the m-BTA/a-BTA copolymers. At low overall concentrations, the decrease in chain length is not very pronounced. At higher concentrations, however, the length decreases more dramatically, and up to $75 \%$ length decrease is observed at $40 \mathrm{mM}$ by mere intercalation of E-m-BTA. When Z-m-BTA acts as a chain capper (blue lines), this trend becomes even more apparent. While at $25 \mu \mathrm{M}$ with $50 \mathrm{~mol} \%$ chain capper added the normalized length decreases to roughly $45 \%$ of the original length, at $40 \mathrm{mM}$ the chains shorten to around $6 \%$ of the original length for as low as $5 \mathrm{~mol} \%$ of chain capper.

Contrary to chain capping in covalent polymers where the ratio of chain capper to monomer controls the chain length, in supramolecular polymers also the concentration, and not just the ratio of chain capper to monomer, majorly affects the aggregate length. ${ }^{8}$ This strong dependence on concentration might seem counterintuitive at first, as it makes the characterization of two-component systems more complex. The analytical techniques used to characterize chain length in supramolecular systems require different concentration regimes, ranging from $25 \mu \mathrm{M}$ for $\mathrm{CD}$ spectroscopy, over $2.0 \mathrm{mM}$ for SLS, to $6 \mathrm{wt} \%(\sim 60 \mathrm{mM})$ for the organogel. This demonstrates that one has to be careful when interpreting data from analytical techniques over a range of concentrations as the results are significantly affected by the concentration regime.

\section{CONCLUSION}

In conclusion, we reported on the copolymerization at thermodynamic equilibrium of achiral alkyl BTAs with a chiral, photoresponsive acyl hydrazone BTA monomer that plays a dual role in the assembly. While E-m-BTA does not form homopolymers, it intercalates into the a-BTA aggregates, inducing a preferred helical sense in the stacks. Upon photoirradiation from the $E$ to the $Z$ isomer, m-BTA reversibly transforms from an intercalator to a chain capper, effectively reducing the average chain length and leading to a macroscopic sol-to-gel transition. By theoretical modeling of the system, we could gain insights into the state of the assembly before and after light stimulus. The model was also used to demonstrate the effect of an intercalator and a chain capper in a twocomponent copolymerization over a broad range of concentrations. The theoretical predictions show that the influence of an additive becomes more and more dramatic with increasing average chain length at higher concentrations.

The present work provides a strategy to control the length and the composition of cooperative supramolecular polymers by using a small amount of responsive comonomer. In the quest for functional out-of-equilibrium systems, new insights are given to translate small molecular changes into macroscopic phase transitions. Moreover, these results highlight the sensitivity of supramolecular systems to concentration and the necessity to characterize supramolecular polymers using various techniques in different concentration regimes.

\section{ASSOCIATED CONTENT}

\section{Supporting Information}

The Supporting Information is available free of charge at https://pubs.acs.org/doi/10.1021/jacs.0c00858.

Experimental procedures, characterization data, details on theoretical modeling, and Figures S1-S27 (PDF)

\section{AUTHOR INFORMATION}

\section{Corresponding Author}

E. W. Meijer - Laboratory of Macromolecular and Organic Chemistry and Institute for Complex Molecular Systems (ICMS), Eindhoven University of Technology, $5600 \mathrm{MB}$ Eindhoven, The Netherlands; (1) orcid.org/0000-0003-41267492; Email: e.w.meijer@tue.nl

\section{Authors}

Elisabeth Weyandt - Laboratory of Macromolecular and Organic Chemistry and Institute for Complex Molecular Systems (ICMS), Eindhoven University of Technology, 5600 $M B$ Eindhoven, The Netherlands

Gijs M. ter Huurne - Laboratory of Macromolecular and Organic Chemistry and Institute for Complex Molecular Systems (ICMS), Eindhoven University of Technology, 5600 $M B$ Eindhoven, The Netherlands

Ghislaine Vantomme - Laboratory of Macromolecular and Organic Chemistry and Institute for Complex Molecular Systems (ICMS), Eindhoven University of Technology, 5600 MB Eindhoven, The Netherlands; 10 orcid.org/0000-00032036-8892

Albert J. Markvoort - Institute for Complex Molecular Systems (ICMS) and Computational Biology Group, Eindhoven University of Technology, 5600 MB Eindhoven, The

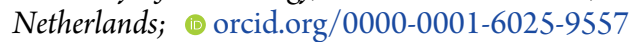

Anja R. A. Palmans - Laboratory of Macromolecular and Organic Chemistry and Institute for Complex Molecular Systems (ICMS), Eindhoven University of Technology, 5600 MB Eindhoven, The Netherlands; (1) orcid.org/0000-00027201-1548

Complete contact information is available at: https://pubs.acs.org/10.1021/jacs.0c00858 


\section{Notes}

The authors declare no competing financial interest.

\section{ACKNOWLEDGMENTS}

This project received funding from the Marie SklodowskaCurie Grant Agreement No. 642083 of the European Union's Horizon 2020 research and innovation program, The Netherlands Organization for Scientific Research (NWO-TOP PUNT Grant No. 10018944, NWO-Veni Grant 722.017.003), and the Dutch Ministry of Education, Culture and Science (Gravitation Program 024.001.035). The ICMS Animation Studio (Eindhoven University of Technology) provided the illustrations of molecules. Huub M. M ten Eikelder is thanked for fruitful discussions on the theoretical models. The authors also thank Marcin L. Ślęczkowski for providing starting materials for the synthesis of the compounds. Mathijs Mabesoone, Fabian Eisenreich, and Lafayette de Windt are acknowledged for the helpful discussions.

\section{REFERENCES}

(1) Adelizzi, B.; Van Zee, N. J.; de Windt, L. N. J.; Palmans, A. R. A.; Meijer, E. W. Future of Supramolecular Copolymers Unveiled by Reflecting on Covalent Copolymerization. J. Am. Chem. Soc. 2019, 141 (15), 6110-6121.

(2) Yang, L.; Tan, X.; Wang, Z.; Zhang, X. Supramolecular Polymers: Historical Development, Preparation, Characterization, and Functions. Chem. Rev. 2015, 115 (15), 7196-7239.

(3) Vantomme, G.; Meijer, E. W. The Construction of Supramolecular Systems. Science (Washington, DC, U. S.) 2019, 363 (6434), 1396-1397.

(4) Michelsen, U.; Hunter, C. A. Self-Assembled Porphyrin Polymers. Angew. Chem., Int. Ed. 2000, 39 (4), 764-767.

(5) Sijbesma, R. P.; Beijer, F. H.; Brunsveld, L.; Folmer, B. J.; Hirschberg, J. H.; Lange, R. F.; Lowe, J. K.; Meijer, E. W. Reversible Polymers Formed from Self-Complementary Monomers Using Quadruple Hydrogen Bonding. Science 1997, 278 (5343), 16011604.

(6) Bellot, M.; Bouteiller, L. Thermodynamic Description of BisUrea Self-Assembly: Competition between Two Supramolecular Polymers. Langmuir 2008, 24 (24), 14176-14182.

(7) Lortie, F.; Boileau, S.; Bouteiller, L.; Chassenieux, C.; Lauprêtre, F. Chain Stopper-Assisted Characterization of Supramolecular Polymers. Macromolecules 2005, 38 (12), 5283-5287.

(8) Knoben, W.; Besseling, N. A. M.; Bouteiller, L.; Cohen Stuart, M. A. Dynamics of Reversible Supramolecular Polymers: Independent Determination of the Dependence of Linear Viscoelasticity on Concentration and Chain Length by Using Chain Stoppers. Phys. Chem. Chem. Phys. 2005, 7 (11), 2390.

(9) De Greef, T. F. A.; Smulders, M. M. J.; Wolffs, M.; Schenning, A. P. H. J.; Sijbesma, R. P.; Meijer, E. W. Supramolecular Polymerization. Chem. Rev. 2009, 109 (11), 5687-5754.

(10) Ogi, S.; Sugiyasu, K.; Manna, S.; Samitsu, S.; Takeuchi, M. Living Supramolecular Polymerization Realized through a Biomimetic Approach. Nat. Chem. 2014, 6 (3), 188-195.

(11) Ogi, S.; Stepanenko, V.; Sugiyasu, K.; Takeuchi, M.; Würthner, F. Mechanism of Self-Assembly Process and Seeded Supramolecular Polymerization of Perylene Bisimide Organogelator. J. Am. Chem. Soc. 2015, 137 (9), 3300-3307.

(12) Kang, J.; Miyajima, D.; Mori, T.; Inoue, Y.; Itoh, Y.; Aida, T. A Rational Strategy for the Realization of Chain-Growth Supramolecular Polymerization. Science (Washington, DC, U. S.) 2015, 347 (6222), 646-651.

(13) Endo, M.; Fukui, T.; Jung, S. H.; Yagai, S.; Takeuchi, M.; Sugiyasu, K. Photoregulated Living Supramolecular Polymerization Established by Combining Energy Landscapes of Photoisomerization and Nucleation-Elongation Processes. J. Am. Chem. Soc. 2016, 138 (43), 14347-14353.
(14) Matsubara, S.; Tamiaki, H. Phototriggered Dynamic and Biomimetic Growth of Chlorosomal Self-Aggregates. J. Am. Chem. Soc. 2019, 141 (3), 1207-1211.

(15) Vantomme, G.; ter Huurne, G. M.; Kulkarni, C.; ten Eikelder, H. M. M.; Markvoort, A. J.; Palmans, A. R. A.; Meijer, E. W. Tuning the Length of Cooperative Supramolecular Polymers under Thermodynamic Control. J. Am. Chem. Soc. 2019, 141 (45), 18278-18285.

(16) Fredy, J. W.; Méndez-Ardoy, A.; Kwangmettatam, S.; Bochicchio, D.; Matt, B.; Stuart, M. C. A.; Huskens, J.; Katsonis, N.; Pavan, G. M.; Kudernac, T. Molecular Photoswitches Mediating the Strain-Driven Disassembly of Supramolecular Tubules. Proc. Natl. Acad. Sci. U. S. A. 2017, 114 (45), 11850-11855.

(17) Bochicchio, D.; Kwangmettatam, S.; Kudernac, T.; Pavan, G. M. How Defects Control the Out-of-Equilibrium Dissipative Evolution of a Supramolecular Tubule. ACS Nano 2019, 13 (4), 4322-4334.

(18) Nelson, A. Engineering Interactions. Nat. Mater. 2008, 7 (7), $523-525$

(19) Yan, X.; Wang, F.; Zheng, B.; Huang, F. Stimuli-Responsive Supramolecular Polymeric Materials. Chem. Soc. Rev. 2012, 41 (18), 6042.

(20) White, T. J.; Broer, D. J. Programmable and Adaptive Mechanics with Liquid Crystal Polymer Networks and Elastomers. Nat. Mater. 2015, 14 (11), 1087-1098.

(21) Kocak, G.; Tuncer, C.; Bütün, V. pH-Responsive Polymers. Polym. Chem. 2017, 8 (1), 144-176.

(22) Ridi, F.; Bonini, M.; Baglioni, P. Magneto-Responsive Nanocomposites: Preparation and Integration of Magnetic Nanoparticles into Films, Capsules, and Gels. Adv. Colloid Interface Sci. 2014, 207 (1), 3-13.

(23) Yao, X.; Li, T.; Wang, J.; Ma, X.; Tian, H. Recent Progress in Photoswitchable Supramolecular Self-Assembling Systems. Adv. Opt. Mater. 2016, 4 (9), 1322-1349.

(24) Yagai, S.; Kitamura, A. Recent Advances in Photoresponsive Supramolecular Self-Assemblies. Chem. Soc. Rev. 2008, 37 (8), 1520.

(25) Zhang, Q.; Qu, D.-H.; Tian, H. Photo-Regulated Supramolecular Polymers: Shining Beyond Disassembly and Reassembly. Adv. Opt. Mater. 2019, 7 (16), 1900033.

(26) Eelkema, R. Photo-Responsive Doped Cholesteric Liquid Crystals. Liq. Cryst. 2011, 38 (11-12), 1641-1652.

(27) Draper, E. R.; Adams, D. J. Photoresponsive Gelators. Chem. Commun. 2016, 52 (53), 8196-8206.

(28) Russew, M.-M.; Hecht, S. Photoswitches: From Molecules to Materials. Adv. Mater. 2010, 22 (31), 3348-3360.

(29) Moran, M. J.; Magrini, M.; Walba, D. M.; Aprahamian, I. Driving a Liquid Crystal Phase Transition Using a Photochromic Hydrazone. J. Am. Chem. Soc. 2018, 140 (42), 13623-13627.

(30) Ryabchun, A.; Li, Q.; Lancia, F.; Aprahamian, I.; Katsonis, N. Shape-Persistent Actuators from Hydrazone Photoswitches. J. Am. Chem. Soc. 2019, 141 (3), 1196-1200.

(31) Pijper, D.; Jongejan, M. G. M.; Meetsma, A.; Feringa, B. L. Light-Controlled Supramolecular Helicity of a Liquid Crystalline Phase Using a Helical Polymer Functionalized with a Single Chiroptical Molecular Switch. J. Am. Chem. Soc. 2008, 130 (13), 4541-4552.

(32) Sackmann, E. Photochemically Induced Reversible Color Changes in Cholesteric Liquid Crystals. J. Am. Chem. Soc. 1971, 93 (25), 7088-7090.

(33) Achalkumar, A. S.; Hiremath, U. S.; Rao, D. S. S.; Prasad, S. K.; Yelamaggad, C. V. Self-Assembly of Hekates-Tris(N -Salicylideneaniline)s into Columnar Structures: Synthesis and Characterization. J. Org. Chem. 2013, 78 (2), 527-544.

(34) Li, T.; Li, X.; Wang, J.; Ågren, H.; Ma, X.; Tian, H. Photoresponsive Supramolecular Assemblies Based on a C3Symmetric Benzene-1,3,5-Tricarboxamide-Anchored Diarylethene. Adv. Opt. Mater. 2016, 4 (6), 840-847.

(35) Heerdt, G.; Tranca, I.; Markvoort, A. J.; Szyja, B. M.; Morgon, N. H.; Hensen, E. J. M. Photoisomerization Induced Scission of Rod- 
like Micelles Unravelled with Multiscale Modeling. J. Colloid Interface Sci. 2018, 510, 357-367.

(36) Zhou, Y.; Xu, M.; Yi, T.; Xiao, S.; Zhou, Z.; Li, F.; Huang, C. Morphology-Tunable and Photoresponsive Properties in a SelfAssembled Two-Component Gel System. Langmuir 2007, 23 (1), 202-208.

(37) Ji, L.; Ouyang, G.; Liu, M. Binary Supramolecular Gel of Achiral Azobenzene with a Chaperone Gelator: Chirality Transfer, Tuned Morphology, and Chiroptical Property. Langmuir 2017, 33, 12419-12426.

(38) Pieraccini, S.; Campitiello, M.; Carducci, F.; Davis, J. T.; Mariani, P.; Masiero, S. Playing Supramolecular Dominoes with Light: Building and Breaking a Photoreversible G-Quadruplex Made from Guanosine, Boric Acid and an Azobenzene. Org. Biomol. Chem. 2019, 17 (10), 2759-2769.

(39) Georgiev, V. N.; Grafmüller, A.; Bléger, D.; Hecht, S.; Kunstmann, S.; Barbirz, S.; Lipowsky, R.; Dimova, R. Area Increase and Budding in Giant Vesicles Triggered by Light: Behind the Scene. Adv. Sci. 2018, 5 (8), 1800432.

(40) Karunakaran, S. C.; Cafferty, B. J.; Jain, K. S.; Schuster, G. B.; Hud, N. V. Reversible Transformation of a Supramolecular Hydrogel by Redox Switching of Methylene Blue-A Noncovalent Chain Stopper. ACS Omega 2020, 5 (1), 344-349.

(41) Su, X.; Aprahamian, I. Hydrazone-Based Switches, MetalloAssemblies and Sensors. Chem. Soc. Rev. 2014, 43 (6), 1963.

(42) Lehn, J. M. From Supramolecular Chemistry towards Constitutional Dynamic Chemistry and Adaptive Chemistry. Chem. Soc. Rev. 2007, 36 (2), 151-160.

(43) Corbett, P. T.; Leclaire, J.; Vial, L.; West, K. R.; Wietor, J.-L.; Sanders, J. K. M.; Otto, S. Dynamic Combinatorial Chemistry. Chem. Rev. 2006, 106 (9), 3652-3711.

(44) Bhat, V. T.; Caniard, A. M.; Luksch, T.; Brenk, R.; Campopiano, D. J.; Greaney, M. F. Nucleophilic Catalysis of Acylhydrazone Equilibration for Protein-Directed Dynamic Covalent Chemistry. Nat. Chem. 2010, 2 (6), 490-497.

(45) Nguyen; Ivan Huc, R. Optimizing the Reversibility of Hydrazone Formation for Dynamic Combinatorial Chemistry. Chem. Commun. 2003, 0 (8), 942.

(46) van Dijken, D. J.; Kovaricek, P.; Ihrig, S. P.; Hecht, S. Acylhydrazones as Widely Tunable Photoswitches. J. Am. Chem. Soc. 2015, 137 (47), 14982-14991.

(47) Cvrtila, I.; Fanlo-Virgós, H.; Schaeffer, G.; Monreal Santiago, G.; Otto, S. Redox Control over Acyl Hydrazone Photoswitches. J. Am. Chem. Soc. 2017, 139 (36), 12459-12465.

(48) Su, X.; Aprahamian, I. Chem Soc Rev Themed Issue: Supramolecular and Dynamic Covalent Reactivity Hydrazone-Based Switches, Metallo-Assemblies and Sensors. Chem. Soc. Rev. 2014, 43 (43), 1963-1981.

(49) Boekhoven, J.; Poolman, J. M.; Maity, C.; Li, F.; van der Mee, L.; Minkenberg, C. B.; Mendes, E.; van Esch, J. H.; Eelkema, R. Catalytic Control over Supramolecular Gel Formation. Nat. Chem. 2013, 5 (5), 433-437.

(50) Kassem, S.; Lee, A. T. L.; Leigh, D. A.; Marcos, V.; Palmer, L. I.; Pisano, S. Stereodivergent Synthesis with a Programmable Molecular Machine. Nature 2017, 549 (7672), 374-378.

(51) Vantomme, G.; Lehn, J. M. Reversible Adaptation to Photoinduced Shape Switching by Oligomer-Macrocycle Interconversion with Component Selection in a Three-State Constitutional Dynamic System. Chem. - Eur. J. 2014, 20 (49), 16188-16193.

(52) Landge, S. M.; Tkatchouk, E.; Benítez, D.; Lanfranchi, D. A.; Elhabiri, M.; Goddard, W. A.; Aprahamian, I. Isomerization Mechanism in Hydrazone-Based Rotary Switches: Lateral Shift, Rotation, or Tautomerization? J. Am. Chem. Soc. 2011, 133, 98129823.

(53) Day, A. C.; Whiting, M. C. Acetone Hydrazone. Org. Synth. 1988, 50, 10-12.

(54) Lefebvre, V.; Cailly, T.; Fabis, F.; Rault, S. Two-Step Synthesis of Substituted 3-Aminoindazoles from 2-Bromobenzonitriles. J. Org. Chem. 2010, 75 (8), 2730-2732.
(55) Stals, P. J. M.; Smulders, M. M. J.; Martín-Rapún, R.; Palmans, A. R. A.; Meijer, E. W. Asymmetrically Substituted Benzene-1,3,5Tricarboxamides: Self-Assembly and Odd-Even Effects in the Solid State and in Dilute Solution. Chem. - Eur. J. 2009, 15 (9), 2071-2080.

(56) Palmans, A. R. A.; Vekemans, J. A. J. M.; Havinga, E. E.; Meijer, E. W. Sergeants-and-Soldiers Principle in Chiral Columnar Stacks of Disc-Shaped Molecules With C3 Symmetry. Angew. Chem., Int. Ed. Engl. 1997, 36 (23), 2648-2651.

(57) Green, M. M.; Reidy, M. P.; Johnson, R. J.; Darling, G.; O'Leary, D. J.; Willson, G. Macromolecular Stereochemistry: The Out-of-Proportion Influence of Optically Active Comonomers on the Conformational Characteristics of Polyisocyanates. The Sergeants and Soldiers Experiment. J. Am. Chem. Soc. 1989, 111 (16), 6452-6454.

(58) He, C.; Lin, Z.; He, Z.; Duan, C.; Xu, C.; Wang, Z.; Yan, C. Metal-Tunable Nanocages as Artificial Chemosensors. Angew. Chem., Int. Ed. 2008, 47 (5), 877-881.

(59) Smulders, M. M. J.; Filot, I. A. W.; Leenders, J. M. A.; van der Schoot, P.; Palmans, A. R. A.; Schenning, A. P. H. J.; Meijer, E. W. Tuning the Extent of Chiral Amplification by Temperature in a Dynamic Supramolecular Polymer. J. Am. Chem. Soc. 2010, 132 (2), 611-619.

(60) Das, A.; Vantomme, G.; Markvoort, A. J.; ten Eikelder, H. M. M.; Garcia-Iglesias, M.; Palmans, A. R. A.; Meijer, E. W. Supramolecular Copolymers: Structure and Composition Revealed by Theoretical Modeling. J. Am. Chem. Soc. 2017, 139 (20), 7036-7044.

(61) ten Eikelder, H. M. M.; Adelizzi, B.; Palmans, A. R. A.; Markvoort, A. J. Equilibrium Model for Supramolecular Copolymerizations. J. Phys. Chem. B 2019, 123 (30), 6627-6642.

(62) ten Eikelder, H. M. M.; Markvoort, A. J. Mass-Balance Models for Scrutinizing Supramolecular (Co)Polymerizations in Thermodynamic Equilibrium. Acc. Chem. Res. 2019, 52 (12), 3465-3474.

(63) Knoben, W.; Besseling, N. A. M. M.; Cohen Stuart, M. A. Chain Stoppers in Reversible Supramolecular Polymer Solutions Studied by Static and Dynamic Light Scattering and Osmometry. Macromolecules 2006, 39 (7), 2643-2653. 